\title{
Data Problem
}

National Cancer Institute

\section{Source}

National Cancer Institute. Data Problem. NCI Thesaurus. Code C91397.

Event in which data (charting, orders, results) is not correctly stored, transferred, updated, or displayed. 